Daniel De Backer

Frédérique Schortgen

\section{Physicians declining patient enrollment in clinical trials: what are the implications?}

Received: 14 October 2013

Accepted: 30 October 2013

Published online: 20 November 2013

(C) Springer-Verlag Berlin Heidelberg and ESICM 2013

D. De Backer (-

Department of Intensive Care, Erasme University Hospital, Université Libre de Bruxelles (ULB), Route de Lennik, 808, 1070, Brussels, Belgium

e-mail: ddebacke@ulb.ac.be

Tel.: +32-2-5553380

Fax: $+32-2-5554698$

F. Schortgen

Department of Intensive Care, Hôpital Henri Mondor, Université Paris XII, Creteil, France

Large collaborative trials, driven by investigators or industry sponsors, have become one of the pillars of evidence-based medicine. However, the results need to be applicable to most of the patients facing the condition that was tested. In this context, the number of patients included in the trial needs to be as close as possible to the number of patients screened. Among the factors responsible for non-inclusion of a patient in a trial (Fig. 1), physician-related issues are probably often neglected. Indeed, one often assumes that the entire ICU team is supporting a trial that is conducted in that ICU. Physician refusals are often not reported [1-5]. When reported, they usually comprise a minority $(<10 \%)$ of the reasons evoked for non-inclusion of critically ill patients in investigator-led clinical trials $[6,7]$. However, this factor is sometimes far from negligible. For example, it was reported in $1,679(15.9 \%)$ of the 10,511 patients not included in the FACTT trial [8], in $130(22.9 \%)$ of the 574 patients not enrolled in the OSCILLATE trial [9], and in $27(33.7 \%)$ of the 80 not enrolled in a trial on external cooling in septic shock [10]. In the December 2013 issue of Intensive Care Medicine, Cook et al. [11] further identified the factors advanced by physicians unwilling to enroll patients in a trial on prophylaxis of thromboembolism (PROTECT study) even though they accepted to contribute to the trial.

The reasons for physicians to decline participation of their patients in the trial may be specific to the trial. In some cases, it may reflect the fact that exclusion criteria were not explicit enough. For example, in the PROTECT study, bleeding risks (bleeding risk, perceived bleeding risk, and peridural catheter) sound like adequate exclusion criteria and these accounted for the first reason for physician refusals $(51 \%)$ [11]. Similarly, in a trial focusing on patients with septic shock treated with high doses of vasopressor agents, physicians were reluctant to enroll socalled moribund patients even though this criterion was not defined in the exclusion criteria [10]. Better definition of exclusion might have prevented some of these physician refusals. In other cases, physicians preferences may reflect the lack of equipoise, at least in some patients. In the FACTT trial, 2,187 (20.8\%) patients, more than twice the number of patients included in the trial, were already equipped with a pulmonary artery catheter at the time of screening [8]. This reflects the physicians' preference for this type of monitoring in a significant proportion of the patients. Similar reasons may be evoked for physicianrelated reasons for not enrolling patients in the OSCILLATE trial [9].

Cook and collaborators identified organizational factors associated with physician refusal and proposed some guidelines to decrease it [11]. Experience of research personnel and closed units decreased the risk of physician refusal to enroll patients. Unfortunately, in many centers research personnel are not available to approach patients or their families for consent. In their recommendation to prevent physician refusal to enroll eligible patients in RCTs, the authors also mentioned pilot trials as a way to 


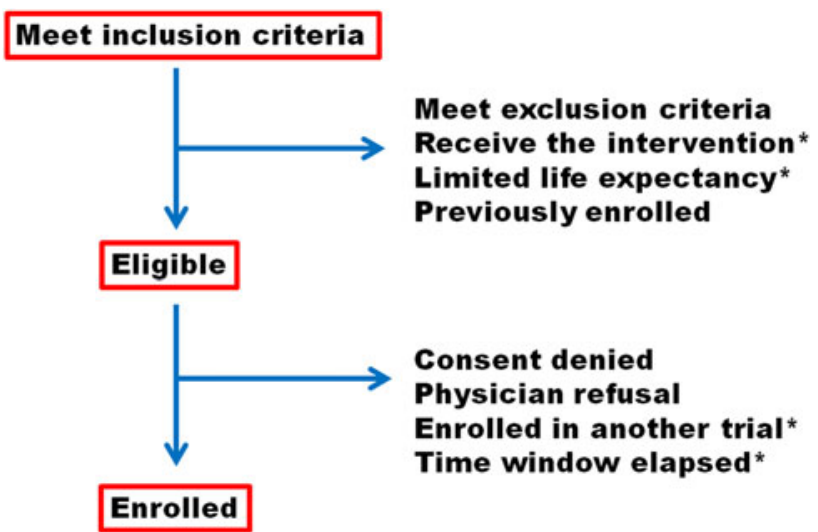

Fig. 1 Factors associated with non-inclusion of patients in clinical trials. In addition to clearly identified physician refusal, some other factors (denoted by asterisks) may be influenced at least in part by physicians preferences

identify the rate of and the reasons for physician decline. The data do not really support this, as a higher rate of physician refusal was observed in the large PROTECT trial than in the pilot study. This suggests that physician behavior is highly variable across the centers and cannot be predicted from pilot studies. In addition, pilot trials are often initiated in the most enthusiastic centers. In trials including very few centers $[12,13]$, physician refusal almost never occurs, but this high adherence to protocol may somewhat lack in centers joining later.

What is the impact of physician refusal to enroll patients on the trial results? First, it impairs the accrual rate and hence the feasibility of the trial. Second it markedly decreases the external validity of the findings. In the FACTT trial, the number of patients not enrolled due to physician refusal was higher than the number of patients included in the trial [8]. Adding these 1,671 patients to the 2,187 patients already equipped with a pulmonary artery catheter means that 3,858 patients were not enrolled because of the physicians' preferences. This extremely high number is almost four times higher than the number of patients included in the trial! This may induce a huge selection bias in the trial. As often no information is provided on non-included patients, it is difficult to evaluate to what extend the included population reflects the population meeting inclusion criteria. In some trials like the FACTT trial [8], it is likely that patients not enrolled for physician-related reasons were either the most severe, in whom physicians deemed the pulmonary artery catheter mandatory, or the less severe, in whom catheter insertion was considered too risky, so that only patients at moderate risk were enrolled. Interestingly, this risk of bias associated with physician refusal does not occur when other reasons lead to non-enrollment of patients. Indeed, refusal of consent by patients and families is more random and does not lead to selection bias.

In conclusion, reluctance of physicians to enroll patients in trials should be minimized, not only as it limits the inclusion rate in trials but mostly as it carries a risk of selection bias. When it occurs, this should be reported and, if possible, the reasons for not including patients should also be collected.

\section{References}

1. Ranieri VM, Thompson BT, Barie PS, Dhainaut JF, Douglas IS, Finfer S, Gardlund B, Marshall JC, Rhodes A, Artigas A, Payen D, Tenhunen J, Al Khalidi HR, Thompson V, Janes J, Macias WL, Vangerow B, Williams MD (2012) Drotrecogin alfa (activated) in adults with septic shock. N Engl J Med 366:2055-2064

2. De Backer D, Biston P, Devriendt J, Madl C, Chochrad D, Aldecoa C, Brasseur A, Defrance P, Gottignies P, Vincent JL (2010) Comparison of dopamine and norepinephrine in the treatment of shock. N Engl J Med 362:779-789
3. Perner A, Haase N, Guttormsen AB, Tenhunen J, Klemenzson G, Aneman A, Madsen KR, Moller MH, Elkjaer JM, Poulsen LM, Bendtsen A, Winding R, Steensen M, Berezowicz P, SoeJensen P, Bestle M, Strand K, Wiis J, White JO, Thornberg KJ, Quist L, Nielsen J, Andersen LH, Holst LB, Thormar K, Kjaeldgaard AL, Fabritius ML, Mondrup F, Pott FC, Moller TP, Winkel P, Wetterslev J (2012) Hydroxyethyl starch 130/0.42 versus Ringer's acetate in severe sepsis. N Engl J Med 367:124-134

4. Lellouche F, Bouchard PA, Simard S, L'Her E, Wysocki M (2013) Evaluation of fully automated ventilation: a randomized controlled study in postcardiac surgery patients. Intensive Care Med 39:463-471
5. van Delden C, Kohler T, BrunnerFerber F, Francois B, Carlet J, Pechere JC (2012) Azithromycin to prevent Pseudomonas aeruginosa ventilatorassociated pneumonia by inhibition of quorum sensing: a randomized controlled trial. Intensive Care Med 38:1118-1125

6. Burns KE, Zubrinich C, Tan W, Raptis S, Xiong W, Smith O, McDonald E, Marshall JC, Saginur R, Heslegrave R, Rubenfeld G, Cook DJ (2013) Research recruitment practices and critically ill patients. A multicenter, cross-sectional study (the consent study). Am J Respir Crit Care Med 187:1212-1218 
7. Guerin C, Reignier J, Richard JC, Beuret P, Gacouin A, Boulain T, Mercier E, Badet M, Mercat A, Baudin O, Clavel M, Chatellier D, Jaber S, Rosselli S, Mancebo J, Sirodot M, Hilbert G, Bengler C, Richecoeur J, Gainnier M, Bayle F, Bourdin G, Leray V, Girard R, Baboi L, Ayzac L (2013) Prone positioning in severe acute respiratory distress syndrome. $\mathrm{N}$ Engl $\mathrm{J}$ Med 368:2159-2168

8. Wheeler AP, Bernard GR, Thompson BT, Schoenfeld D, Wiedemann HP, deBoisblanc B, Connors AF Jr, Hite RD, Harabin AL (2006) Pulmonaryartery versus central venous catheter to guide treatment of acute lung injury. N Engl J Med 354:2213-2224

9. Ferguson ND, Cook DJ, Guyatt GH, Mehta S, Hand L, Austin P, Zhou Q, Matte A, Walter SD, Lamontagne F, Granton JT, Arabi YM, Arroliga AC, Stewart TE, Slutsky AS, Meade MO (2013) High-frequency oscillation in early acute respiratory distress syndrome. N Engl J Med 368:795-805
10. Schortgen F, Clabault K, Katsahian S, Devaquet J, Mercat A, Deye N, Dellamonica J, Bouadma L, Cook F, Beji O, Brun-Buisson C, Lemaire F, Brochard L (2012) Fever control using external cooling in septic shock: a randomized controlled trial. Am J Respir Crit Care Med 185:1088-1095

11. Cook D, Arabi Y, Ferguson ND, HeelsAnsdell D, Freitag A, McDonald E, Clarke F, Keenan S, Pagliarello G, Plaxton W, Herridge M, Karachi T, Vallance S, Cade J, Crozier T, da Silva SA, Costa FR, Brandao N, Watpool I, McArdle T, Hollinger G, Mandourah Y, Al Hazmi M, Zytaruk N, Adhikari NK (2013) Physicians declining patient enrollment in a critical care trial: a case study in thromboprophylaxis. Intensive Care Med 39:2115-2125. doi: 10.1007/s00134-013-3074-X
12. Le Guen M, Liu N, Bourgeois E, Chazot T, Sessler DI, Rouby JJ, Fischler M (2013) Automated sedation outperforms manual administration of propofol and remifentanil in critically ill patients with deep sedation: a randomized phase II trial. Intensive Care Med 39:454-462

13. Bjelland TW, Dale O, Kaisen K, Haugen BO, Lydersen S, Strand K, Klepstad P (2012) Propofol and remifentanil versus midazolam and fentanyl for sedation during therapeutic hypothermia after cardiac arrest: a randomised trial. Intensive Care Med 38:959-967 